\title{
Updating of aversive memories after temporal error detection is differentially modulated by mTOR across development
}

\author{
Lucille Tallot, ${ }^{1,2,3,4}$ Lorenzo Diaz-Mataix, ${ }^{2,3}$ Rosemarie E. Perry, ${ }^{2,3,4}$ Kira Wood, $^{2,3,4}$ \\ Joseph E. LeDoux, ${ }^{2,3}$ Anne-Marie Mouly, ${ }^{5}$ Regina M. Sullivan, ${ }^{2,3,4}$ and Valérie Doyère ${ }^{1,2}$ \\ ${ }^{1}$ Institut des Neurosciences Paris-Saclay (Neuro-PSI), UMR 9197, Université Paris Sud, CNRS, Université Paris Saclay, 91405 Orsay, \\ France; ${ }^{2}$ Emotional Brain Institute, Center for Neural Science, New York University, New York, New York 10003, USA; ${ }^{3}$ Emotional Brain \\ Institute, Nathan Kline Institute, Orangeburg, New York 10962, USA; ${ }^{4}$ Child Study Center Institute for Child and Adolescent \\ Psychiatry, New York University Langone Medical Center, New York, New York 10016, USA; ${ }^{5}$ Centre de Recherche en Neurosciences de \\ Lyon, CNRS UMR 5292-INSERM U1028-Université Lyon 1, France
}

\begin{abstract}
The updating of a memory is triggered whenever it is reactivated and a mismatch from what is expected (i.e., prediction error) is detected, a process that can be unraveled through the memory's sensitivity to protein synthesis inhibitors (i.e., reconsolidation). As noted in previous studies, in Pavlovian threat/aversive conditioning in adult rats, prediction error detection and its associated protein synthesis-dependent reconsolidation can be triggered by reactivating the memory with the conditioned stimulus (CS), but without the unconditioned stimulus (US), or by presenting a CS-US pairing with a different CS-US interval than during the initial learning. Whether similar mechanisms underlie memory updating in the young is not known. Using similar paradigms with rapamycin (an mTORCl inhibitor), we show that preweaning rats (PN18-20) do form a long-term memory of the CS-US interval, and detect a 10-sec versus 30-sec temporal prediction error. However, the resulting updating/reconsolidation processes become adult-like after adolescence (PN30-40). Our results thus show that while temporal prediction error detection exists in preweaning rats, specific infant-type mechanisms are at play for associative learning and memory.
\end{abstract}

Learning or memory updating based on prediction error detection, when an event differs from what was predicted, enables the organism to adapt to changing circumstances. During Pavlovian aversive conditioning in adults, the conditioned stimulus (CS) acquires a predictive value for the unconditioned stimulus (US), including when it is due to arrive, in as few as one trial (Davis et al. 1989; Díaz-Mataix et al. 2013). Error detection in this context depends heavily on the capacity to detect and memorize the interval between the CS and the US, and is critical for triggering the updating of aversive memories, in an amygdala-dependent manner (DíazMataix et al. 2013).

Animals as young as postnatal (PN) day 10 can learn about aversive associations, as their amygdala becomes adult-like (Sullivan et al. 2000). However, several studies have highlighted how the mechanisms underlying aversive memory formation in pups are not identical to those used in adulthood (Sullivan et al. 2000; Moriceau and Sullivan 2006, for recent reviews, see Pattwell et al. 2013; Tallot et al. 2015). With regard to learning the CS-US interval in pups, only a few studies exist (for review, see Tallot et al. 2015), and they have focused on the development of temporally regulated behaviors during training, rather than long-term memory of the interval. Timed eyeblink conditioning has been observed in PN17-18 rat pups only after more than 200 conditioning training trials (Stanton et al. 1992). More recently, Boulanger Bertolus et al. (2014) have shown patterns of breathing and freezing related to the CS-US interval within a single

\footnotetext{
Corresponding authors: lucille.tallot@gmail.com; valerie.doyere@ u-psud.fr

Article is online at http://www.learnmem.org/cgi/doi/10.1101//m.043083. 116.
}

session of 10 pairings of an olfactory aversive conditioning in rat pups as young as PN12, although the temporal pattern was not similar to the one observed in adults. The aforementioned studies do not inform us on whether learning interval times early in life creates consolidated long-term memories, which would allow for temporal prediction error and memory updating in young animals, as in adults.

In adult rats, the updating of a memory after prediction error detection results in reconsolidation, which requires the synthesis of new proteins (e.g., Nader et al. 2000, for review, see Sara 2000). It has been shown that temporal error detection, by presenting a trial with a changed CS-US interval $24 \mathrm{~h}$ after consolidation of a CS-US memory, also triggers reconsolidation (Díaz-Mataix et al. 2013; Alfei et al. 2015). Disruption of the reconsolidation of auditory threat/aversive conditioning in adults has been demonstrated by showing that intra-amygdala infusion or intraperitoneal injection of protein synthesis inhibitors, immediately after memory reactivation and prediction error detection, results in a reduced level of freezing when memory is tested $24 \mathrm{~h}$ later by presenting unreinforced CSs (e.g., Nader et al. 2000; Blundell et al. 2008; Díaz-Mataix et al. 2013; Mac Callum et al. 2014). As disruption of reconsolidation is observed only when a prediction error is detected, it provides a mean to test under which conditions the animal is able to detect changes compared with the previous

C 2017 Tallot et al. This article is distributed exclusively by Cold Spring Harbor Laboratory Press for the first 12 months after the full-issue publication date (see http://learnmem.cshlp.org/site/misc/terms.xhtml). After 12 months, it is available under a Creative Commons License (Attribution-NonCommercial 4.0 International), as described at http://creativecommons.org/licenses/by$\mathrm{nc} / 4.0 /$. 
learning, and to enter in an updating process. Here, we thus used a reconsolidation paradigm to test whether PN18-20 rat pups can detect temporal errors in a CS-US association once the Pavlovian aversive leaning has been consolidated in a long-term memory, and whether they can update their memory in a reconsolidation process similar to the one described in adults.

\section{Results}

To assess memory updating induced by temporal error detection in preweaning rats we used a 40 -sec tone CS with a footshock arriving either 10 or $30 \mathrm{sec}$ after the tone onset. The memory was reactivated with either an unreinforced CS or a single CS-US trial with a different CS-US interval compared with training, both of those conditions should produce prediction error. As a control, the memory was reactivated using the same conditions as during training, which should not produce prediction error. The impact of a single intraperitoneal injection of rapamycin $(20 \mathrm{mg} / \mathrm{kg}) \mathrm{im}$ mediately after memory reactivation was assessed $24 \mathrm{~h}$ later using an unreinforced CS (post-reactivation long-term memory test; PR-LTM). For all the described experiments, no significant difference in freezing levels was observed for the pre-CS period between vehicle and rapamycin groups (see Table 1). Also, sampling pups among the different sets, we found no effect of the injection of rapamycin on the weight of the pups $24 \mathrm{~h}$ after the injection compared with the injection of vehicle (mean \pm SEM for vehicle $=$ $42.1 \pm 1.60 \mathrm{~g}$ and rapamycin $=42.7 \pm 1.61 \mathrm{~g}, t_{(44)}=0.13$, n.s.). The nature of the protocol used in these experiments might introduce bias when comparing freezing among groups that have experienced the US at different time intervals. However, none of the groups have ever experienced the US in the first $10 \mathrm{sec}$ of the tone, making it a time window in which the comparisons are not influenced by anything other than expectation. We therefore chose to present the results obtained only for the first $10 \mathrm{sec}$ of the tone stimulus for both reactivation and PR-LTM sessions.

\section{Cued aversive memory updating is present in preweaning pups}

Reconsolidation has been demonstrated in pups as young as PN3 in a conditioned taste aversion paradigm (Languille et al. 2008). However, conditioned taste aversion does not rely on precise CS-US timing and involves a different neural network than the traditional Pavlovian aversive conditioning in young pups (Shionoya et al. 2006). Whether reconsolidation of a cued aversive conditioning can be disrupted in preweaning pups has yet to be tested. We chose to use rapamycin, as it is an inhibitor of mTORC1, which is involved in a pathway that includes PI3K, $\mathrm{AKT}$, and $\mathrm{PKB}$, and modulation of most of these molecular targets has an effect on reconsolidation (for review, see Baldi and Bucherelli 2015). We tested whether a single injection of rapamycin, immediately after memory reactivation with a CS alone, produces an impairment of CS-US long-term memory, as expressed by a decrease in freezing to the CS during the PR-LTM test. Prediction error processes depend on the ability to detect differences between an initial learning and a new event related to the previous one. As initial learning may be weaker in pups, we tested two strengths of conditioning (5 CS-US and 10 CS-US pairings) to determine their effect on prediction error detection.

Freezing behavior during reactivation and during the PRLTM test is shown in Figure 1. After training with five CS-US pairings, there was a trend for a reduced amount of freezing during the PR-LTM test in the rapamycin group when compared with the vehicle group $\left(t_{(22)}=1.84, P=0.078\right.$, Fig. $\left.1 \mathrm{~A}\right)$, while they did not differ during the reactivation session $\left(t_{(22)}=0.56\right.$, n.s.). When trained with 10 CS-US pairings, the reduction in freezing during PR-LTM in the rapamycin group compared with the vehicle group reached significance $\left(t_{(22)}=3.03, P=0.006\right.$, Fig. $\left.1 \mathrm{~B}\right)$, but did not differ during reactivation $\left(t_{(22)}=0.57\right.$, n.s.). Thus, the CS alone reactivation triggered a memory updating that was modulated by the injection of rapamycin in preweaning rats, as long as sufficient initial training was provided. This result suggests that when the initial learning has not reached a plateau, the subject may still be uncertain and thus have more difficulty in detecting a difference between training and reactivation, resulting in a reduced likelihood of triggering memory reconsolidation mechanisms. Alternatively, poorer learning of the CS-US interval in the five CS-US conditioning group may have rendered the subjects not capable of expecting the US precisely enough, and thus prevented the detection of prediction error with a 40 -sec CS presentation, similarly to reports showing a lack of reconsolidation when the CS is terminated before the expected US arrival during the reactivation (Suzuki et al. 2004; Alfei et al. 2015). In any case, in order to ascertain the most stable conditions, we have therefore chosen to use a conditioning of 10 CS-US pairings for all subsequent experiments.

\section{Preweaning rats can detect changing CS-US time intervals}

We next tested whether a change in the CS-US interval between 10 and 30 sec would be detected by PN18-20 pups as a temporal prediction error and would trigger a reconsolidation process, as has been reported previously in adults (Díaz-Mataix et al. 2013). The authors showed that, in adults, reactivating a memory with a single CS-US pairing triggered a reconsolidation process, and that a protein synthesis inhibitor disrupted this process, only when a change in the CS-US interval was detected. We thus tested the effect of rapamycin in preweaning animals when the reactivation consisted of a single pairing with a modified CS-US interval (Shift groups), either from 30 to $10 \mathrm{sec}$ (Earlier), from 10 to $30 \mathrm{sec}$ (Later), or when the CS-US interval was not changed (No Shift

Table 1. Percentage of freezing ( \pm SEM) during pre-CS period for reactivation and post-reactivation long-term memory test (PR-LTM)

\begin{tabular}{|c|c|c|c|c|c|c|c|c|c|}
\hline \multirow[b]{2}{*}{ Group } & & \multicolumn{4}{|c|}{ Reactivation } & \multicolumn{4}{|c|}{ PR-LTM } \\
\hline & & Vehicle & Rapamycin & $t$-test & $P$ & Vehicle & Rapamycin & $t$-test & $P$ \\
\hline \multirow[t]{5}{*}{ Preweaning rats } & CS alone (5 CS-US) & $26.2 \pm 8.5$ & $19.7 \pm 5.7$ & $t_{(22)}=0.64$ & n.s. & $35.6 \pm 6.2$ & $20.9 \pm 4.7$ & $t_{(22)}=1.92$ & n.s. \\
\hline & CS alone (10 CS-US) & $29.3 \pm 4.8$ & $16.3 \pm 4.6$ & $t_{(22)}=1.96$ & n.s. & $25.6 \pm 5.9$ & $16.7 \pm 4.3$ & $t_{(22)}=1.21$ & n.s. \\
\hline & Shift & $34.6 \pm 4.5$ & $47.1 \pm 4.5$ & $t_{(46)}=1.96$ & n.s. & $34.3 \pm 5.6$ & $45.3 \pm 5.3$ & $t_{(46)}=1.44$ & n.s. \\
\hline & No shift & $38.1 \pm 6.4$ & $39.4 \pm 6.4$ & $t_{(46)}=0.14$ & n.s. & $27.0 \pm 5.6$ & $36.2 \pm 6.6$ & $t_{(46)}=1.27$ & n.s. \\
\hline & No reactivation & & & & & $7.6 \pm 2.9$ & $6.4 \pm 2.2$ & $t_{(21)}=0.32$ & n.s. \\
\hline \multirow[t]{2}{*}{ Adolescents } & Shift $20 \mathrm{mg} / \mathrm{kg}$ & $35.2 \pm 11.7$ & $28.6 \pm 9.4$ & $t_{(21)}=0.44$ & n.s. & $21.0 \pm 5.3$ & $10.7 \pm 5.5$ & $t_{(21)}=1.36$ & n.s. \\
\hline & Shift $40 \mathrm{mg} / \mathrm{kg}$ & $32.0 \pm 8.1$ & $17.5 \pm 5.0$ & $t_{(22)}=1.52$ & n.s. & $38.3 \pm 10.9$ & $43.4 \pm 11.1$ & $t_{(22)}=0.33$ & n.s. \\
\hline \multirow[t]{2}{*}{ Adults } & Shift $20 \mathrm{mg} / \mathrm{kg}$ & $14.1 \pm 7.5$ & $4.73 \pm 1.9$ & $t_{(23)}=1.09$ & n.s. & $40.4 \pm 9.1$ & $31.4 \pm 8.3$ & $t_{(23)}=0.70$ & n.s. \\
\hline & Shift $40 \mathrm{mg} / \mathrm{kg}$ & $12.1 \pm 5.1$ & $13.6 \pm 5.1$ & $t_{(26)}=0.21$ & n.s. & $23.5 \pm 8.9$ & $20.1 \pm 6.2$ & $t_{(26)}=0.32$ & n.s. \\
\hline
\end{tabular}


A
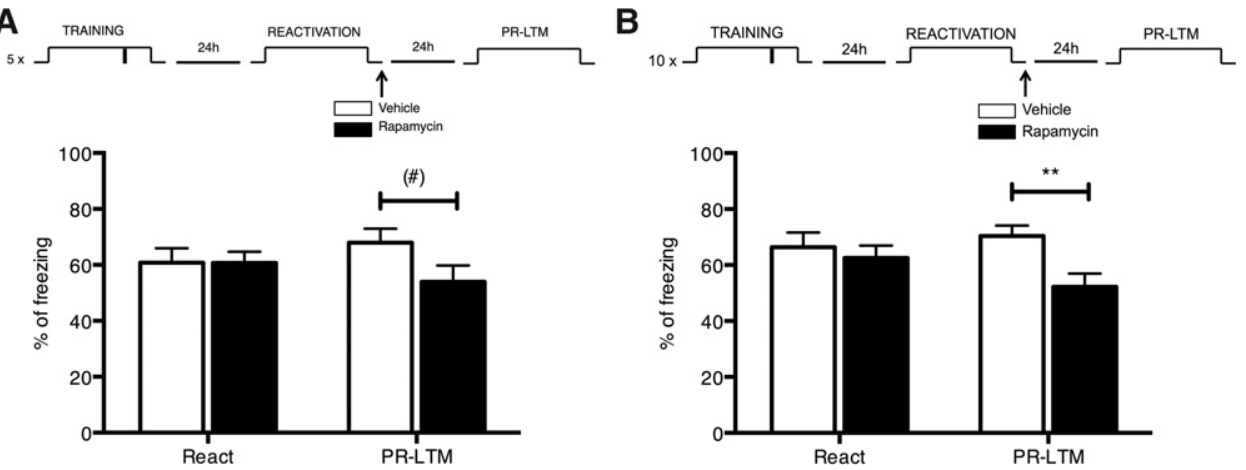

Figure 1. Rapamycin impairs long-term memory in PN18-20 pups after reactivation with CS alone. The two experiments consisted of training with either $5(A)$ or $10(B)$ trials of a 40 -sec tone (CS) paired with a US footshock delivered $30 \mathrm{sec}$ after tone onset. Rats were reactivated with the presentation of a single CS alone trial. Each panel shows a schematic of the experimental design (top) and the percentage of freezing (mean + SEM) to the first 10 sec of the CS during reactivation with a single CS alone (React) and during the post-reactivation long-term memory test (PR-LTM) in rat pups injected with vehicle (white bars) or with rapamycin (black bars) (bottom). Freezing during reactivation was equivalent between vehicle and rapamycin groups in both experiments. Injection of rapamycin in rats trained with five CS-US pairings $(A)$ produced a trending impairment of memory during PR-LTM, whereas training with 10 CS-US pairings $(B)$ provoked a significant impairment. $n=12$ for each group, $(\#) P=0.08,(* *) P<0.01$.

groups, $30-30 \mathrm{sec}$ or $10-10 \mathrm{sec}$ ). If the reactivation triggers an updating of the memory, the rapamycin should disrupt the reconsolidation of this memory and produce lower levels of freezing during PR-LTM (as in Fig. 1).

Surprisingly preweaning animals injected with rapamycin after memory reactivation with a shift in the time of arrival of the shock showed higher levels of freezing during PR-LTM compared with the vehicle group $\left(t_{(46)}=3.71, P<0.001\right.$, Fig. $\left.2 \mathrm{~A}\right)$, while there was no difference during the reactivation session $\left(t_{(46)}=0.59\right.$, n.s. $)$. The Earlier and Later sub-groups were pooled as there were no differential effects of the drug between the two conditions (group $\times$ drug interaction for both reactivation and PR-LTM: $F_{(1,44)}<0.8$, n.s.). However, when rapamycin was injected after reactivating with the same CS-US interval as during training, no significant difference was observed with the vehicle group during PR-LTM $\left(t_{(46)}=0.23\right.$, n.s.) or reactivation $\left(t_{(46)}=0.23\right.$, n.s., Fig. 2B). The $30-30 \mathrm{sec}$ and $10-10 \mathrm{sec}$ subgroups were pooled as there were no differential effects of the drug between the two conditions (group $\times$ drug interaction for both reactivation and PR-LTM: $F_{(1,44)}<0.55$, n.s.).

As a further control, we tested the effect of rapamycin without reactivation and saw no difference between rapamycin and vehicle groups during the PR-LTM test $\left(t_{(21)}=0.62\right.$, n.s.). Thus, the increase in freezing observed when the CS-US interval during reactivation was modified compared with training is selectively due to an effect of rapamycin on a process triggered by the detection of a mismatch in the CS-US time interval. Our controls show that injection of rapamycin alone (No reactivation) or in combination with a footshock (No shift) do not enhance freezing in PR-LTM test. Overall these results demonstrate that temporal prediction error can be detected by rat pups and trigger a process sensitive to rapamycin, albeit resulting in a modulation of behavior in an unexpected direction.

Freezing is notoriously poor at evidencing temporal patterns in US expectancy. We further analyzed the temporal pattern of freezing throughout the CS during PR-LTM, as it may nevertheless be indicative of the temporal expectancy of the US and bring some insights on the effects of the reactivation/drug condition might have on the memory of the CS-US interval (Díaz-Mataix et al. 2013; Boulanger Bertolus et al. 2014). Differential temporal patterns were observed between the two no-shift conditions for which the CS-US interval was kept constant between training and reactivation (Fig. 3A, 30 $\rightarrow 30$ and $3 \mathrm{~B}, 10 \rightarrow 10$ ), albeit the
Time $\times$ CS-US interval interaction reached significance only when pooling vehicle and rapamycin subjects within the same CS-US interval condition $\left(F_{(12,552)}=1.839, P<0.05\right)$. Therefore, during PR-LTM, rat pups tended to respond differentially depending on the CS-US duration they learned, although more training could have resulted in better defined patterns (Drew et al. 2005). Whereas when both durations were presented, the preweaning rats' freezing curve was somewhat intermediate and similar no matter which duration was learned first (see Fig. 3E,F). Noticeably, the differential temporal pattern observed here converges with the temporal error detection findings reported above in indicating that, at this age, rat pups are able to detect and memorize durations over several days.

The previously described increase in freezing could be due to a different response to the US when it is unexpected versus expected during the reactivation session for preweaning rats compared with adults. Figure 4 presents the response to the US during the reactivation session, expressed as the percent change in freezing during the $10 \mathrm{sec}$ immediately after the shock delivery compared with the $10 \mathrm{sec}$ immediately preceding the shock. For PN18-20 pups (Fig. 4A), when there was no surprise (i.e., the shock arrived at the same time as during conditioning) we observed a significant decrease in freezing following the shock $\left(30-30 \mathrm{sec}, t_{(23)}=7.32\right.$, $\left.P<0.001 ; 10-10 \mathrm{sec}, t_{(23)}=4.82, P<0.001\right)$. A similar decrease was observed in the group that received the shock later than expected $\left(t_{(23)}=8.25, P<0.001\right)$. When the shock was delivered earlier than expected, however, no significant change in the amount of freezing was observed $\left(t_{(23)}=0.09\right.$, n.s.).

For comparison, we analyzed data from adult rats submitted to similar conditions (Fig. 4B, data taken from the experiment published in Díaz-Mataix et al. (2013), but that were not reported) and observed a similar pattern of response. The 30-30 sec group and the Later group showed both a significant decrease in freezing after the shock $\left(t_{(15)}=6.46, P<0.001\right.$ and $t_{(10)}=4.87, P<0.001$, respectively), whereas the Earlier group showed no significant change in level of freezing $\left(t_{(11)}=0.64\right.$, n.s.). In sum, while the delivery of the US at an unexpected time had a different impact on the freezing level depending on whether it arrives earlier or later than expected, the impact was similar for pups and adult rats. Therefore, it is unlikely that a differential response to the footshock during reactivation in PN18-20 pups was responsible for the increase in freezing during PR-LTM in the Shift-rapamycin group (Fig. 2A). 

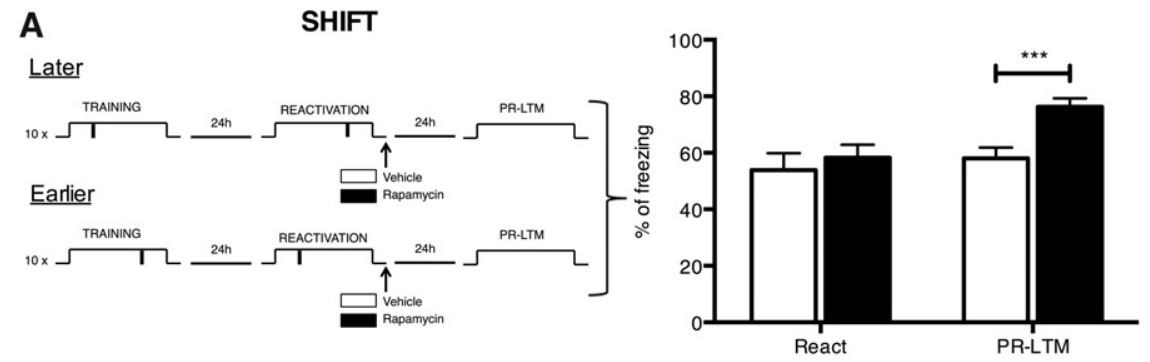

B

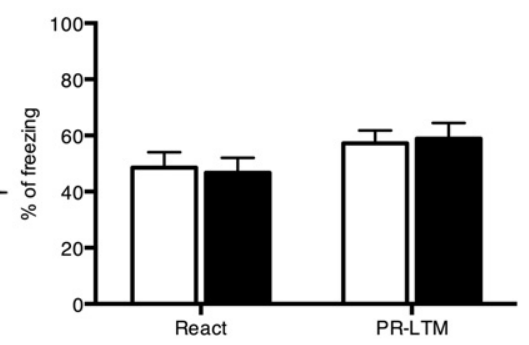

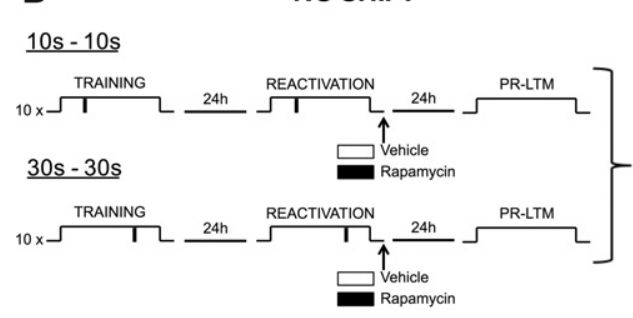

C

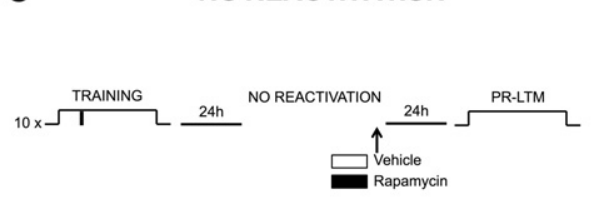

NO REACTIVATION

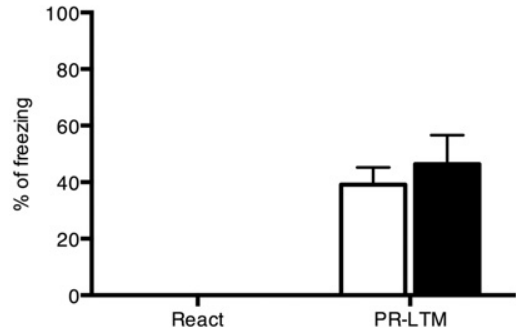

Figure 2. Preweaning rats can detect a change in CS-US interval. All experiments consisted of training with 10 trials of a 40-sec tone (CS) paired with a US footshock delivered 30 or 10 sec after tone onset. Each panel shows a schematic of the experimental design (left) and the percentage of freezing $($ mean + SEM) in the first $10 \mathrm{sec}$ of the CS during reactivation (React) and during the post-reactivation long-term memory (PR-LTM) test in rat pups injected with vehicle (white bars) or with rapamycin (black bars) (right). Freezing during reactivation was equivalent between vehicle and rapamycin groups in all experiments. $(A)$ Rats reactivated with a different CS-US time interval compared with the one learned during training and injected with rapamycin, whether it was for an earlier $(30-10 \mathrm{sec}, n=12$ per group) or for a later (10-30 sec, $n=12$ per group) time, showed a significant increase in freezing during the PR-LTM test. $(B)$ Rats reactivated with the same CS-US time interval as the one learned during training (10-10 sec, $n=12$ per group; $30-30 \mathrm{sec}, n=12$ per group) showed no effect of rapamycin on freezing in a PR-LTM test. (C) Similarly, rats that were not reactivated showed no effect of rapamycin on freezing in a PR-LTM test $\left(n=11\right.$ for rapamycin and 12 for vehicle). $\left({ }^{* * *}\right) P<0.001$. lescent rats showed no effect of rapamycin during the PR-LTM test $\left(t_{(22)}=1.19\right.$, n.s., Fig. 5A) nor during the reactivation $\left(t_{(22)}=0.54\right.$, n.s.). We additionally verified that a $20 \mathrm{mg} / \mathrm{kg}$ dose of rapamycin (i.e., the one used in the preweaning rats) did not result in an increase in freezing during PR-LTM in adolescents or adults. At this lower dose, rapamycin lost its effects on reconsolidation in adults (mean $\% \pm$ SEM of freezing for vehicle $=54.3 \pm 6.24$ and rapamycin $=$ $50.3 \pm 4.62, t_{(23)}=0.98$, n.s.), and remained inefficient in adolescents (mean $\% \pm$ SEM of freezing for vehicle $=$ $64.4 \pm 7.78$ and rapamycin $=52.3 \pm$ $7.48, t_{(21)}=1.12$, n.s.). Therefore, the increase in freezing that we observed in PN18-20 pups after injection of rapamycin seems to be specific to this age range and the adult-like pattern is not reached until after PN40 at least. It seems highly unlikely that the absence of rapamycin-induced changes in adolescents could be due to a loss of the ability to detect or to memorize the changing CS-US interval and instead it seems more logical to think it is due to a progressive shift toward a more adult-like mechanism of memory updating.

\section{Discussion}

The present study showed that prediction error detection can trigger a protein synthesis-dependent memory update in PN18-20 rats. This was shown through a modification in freezing response to the CS in long-term memory when rapamycin was injected immediately after memory reactivation with a CS alone or a CS-US trial with a different CS-US interval, whereas no effect was observed when the memory had not been reactivated, or when there was no prediction error detection.

One important result of our study is that we show, for the first time, that

\section{Effect of rapamycin on reconsolidation across} development: adolescents and adults

To further explore the potential developmental difference in updating memory, we also tested adolescent (PN30-40) and adult rats $(>$ PN60) using the same procedure conducted in rat pups but with a higher concentration of rapamycin $(40 \mathrm{mg} / \mathrm{kg})$ as used in the literature (Blundell et al. 2008; Mac Callum et al. 2014) to take into account the differing permeability of the blood brain barrier (Saunders et al. 2012). For each age, we compared the Later shift condition during reactivation, meaning that rapamycin or vehicle was injected immediately after a shift in CS-US interval from 10 to $30 \mathrm{sec}$. As expected and in agreement with previous studies (e.g., Nader et al. 2000; Blundell et al. 2008; Díaz-Mataix et al. 2013; Mac Callum et al. 2014), adults showed a decrease in freezing in the rapamycin group, showing an impairment of reconsolidation, $\left(t_{(26)}=2.43, P<0.05\right.$, Fig. 5B) but no difference during reactivation $\left(t_{(26)}=0.83\right.$, n.s.). In contrast, ado- preweaning rats can memorize and remember, for at least $24 \mathrm{~h}$, a CS-US interval. Studies in human infants have shown that they can detect a temporal change in a repeating pattern of stimuli (Clifton 1974; Brannon et al. 2004). Human infants, as young as of a glucose reward when it was omitted for the first time (Clifton 1974). Another study looked at 10-mo-old babies and showed a frontal cortex event-related potential (ERP) modulation in response to a stimulus deviant from trained temporal regularity, also called oddball stimulus. This response was similar to the one seen in adults (Brannon et al. 2004). Previous studies in rat pups have shown behavioral temporal pattern compatible with an interval-dependent temporal expectation during learning (Stanton et al. 1992; Boulanger Bertolus et al. 2014; for review, see Tallot et al. 2015). All these studies, however, did not inform us on whether there was formation of a long-term (i.e., at least $24 \mathrm{~h}$ ) memory of that interval. Our results demonstrate that it is 1-3 d old, showed a decrease in heart rate at the expected time 

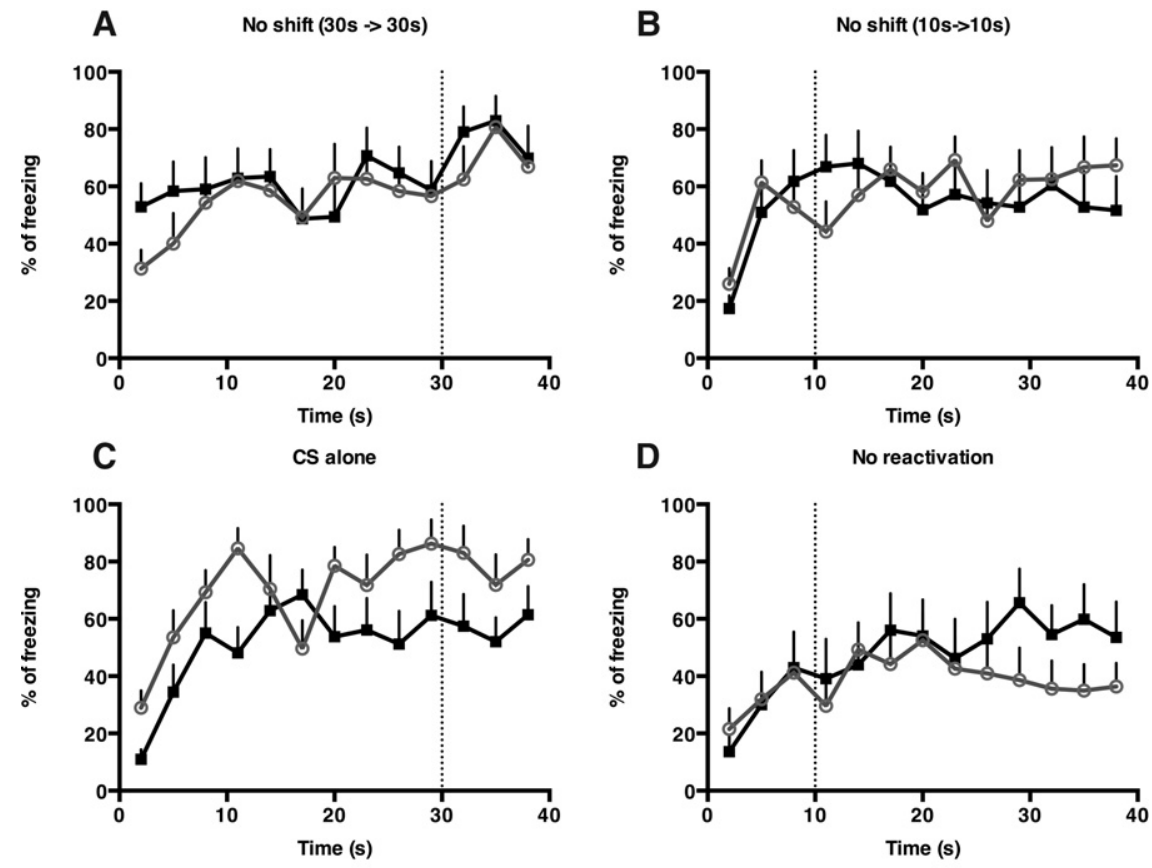

D
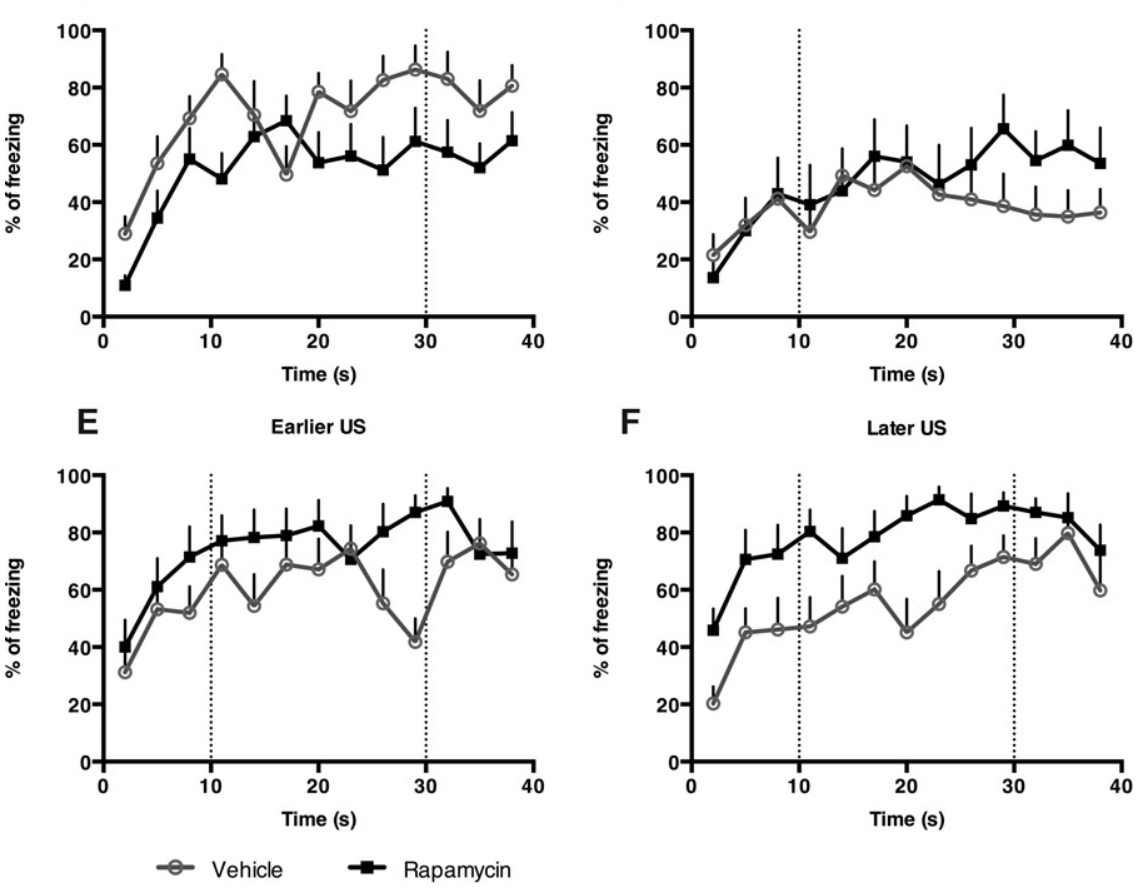

Figure 3. Temporal pattern of freezing in post-reactivation long-term memory test (PR-LTM) in PN18-20 rats. For each experimental group, the percentage of freezing for each 3-sec bin is represented across the duration of the CS for the post-reactivation long-term memory (PR-LTM) test. There was a significant effect of time and no significant Drug $\times$ Time interaction in every condition (all $F_{s}>3.22$, $P<0.001$ for Time, and Fs $<1.45$, n.s. for Drug $\times$ Time interaction).

the case, at least for PN18-20 rats, and raise questions about the underlying neurobiological network involved in interval timing. Interval timing is usually considered to depend on a corticostriatal network (for review, see Buhusi and Meck 2005; Meck et al. 2008), and in preweaning rats both prefrontal cortex (Nonneman and Corwin 1981; Van Eden and Uylings 1985; Casey et al. 2005) and striatum (Boulanger Bertolus et al. 2014) are usually considered to be immature. However, in the case of Pavlovian threat conditioning, the amygdala may play a role in processing the CS-US interval and detecting temporal errors (for review, see Díaz-Mataix et al. 2014b), and this brain area is known to present adult-like function starting at PN10 (Sullivan et al. 2000). Therefore, it is possible that young rats use a different network from the cortico-striatal one described in adults. This preweaning network may involve the amygdala and be sufficient for timing and processing CS-US intervals even if more complicated temporal tasks may be deficient.

Another important and unexpected finding from our study is that the attempt to block reconsolidation when shifting the CSUS interval in rat pups resulted in an increase in freezing, that is, freezing to the CS might be expected in the CS alone group, due to contingency degradation, whereas in the Shift group, the competition of the memories of the two durations produced stronger freezing, due to increased uncertainty of the time of arrival of the US. In the No Shift groups, there was no prediction error detection and thus no updating of memory. How the equilibrium in trace dominance evolves during development is not known, but our results point to this interesting issue that will need to be addressed in further investigations.

Through which mechanisms can rapamycin enhance the reactivated memory in PN18-20 pups? A number of possibilities come to mind. For example, the neural circuits involved in reconsolidation of aversive memory and temporal memory may not be completely mature (with some of the structures mature but not others), thus tipping the balance of activity in this network and producing opposite results to what is observed in adults. Alternatively, rapamycin could act on neurogenesis, as neurogenesis is stronger in younger animals. In effect, post-natal neurogenesis has been observed in the amygdala (Bernier et al. 2002) and these new neurons seem to be involved in cued threat memory in adults (Hung et al. 2015). The addition of new neurons can 
A

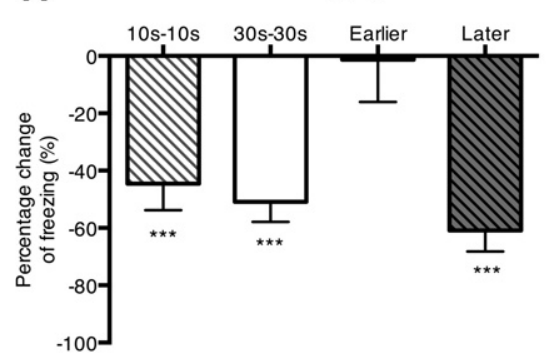

B

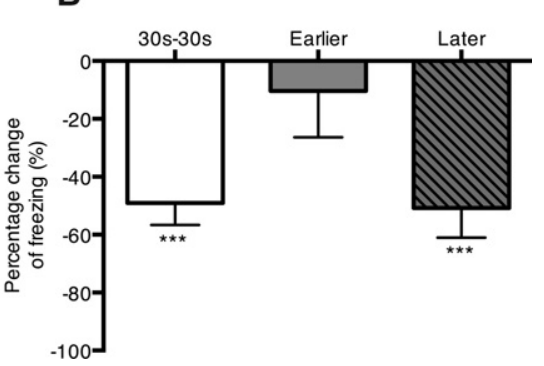

Materials and Methods

\section{Subjects}

Preweaning: We used male and female PN18-20 Long Evans rats born and bred in our colony (originally from Harlan Laboratories). A total of 167 pups were conditioned. Rats were housed in polypropylene cages $(34 \times 29 \times 17$ $\mathrm{cm}$ ) with their mother and littermates and maintained in a $20^{\circ} \mathrm{C} \pm 1^{\circ} \mathrm{C}$ environment with a $12 / 12 \mathrm{~h}$ light-dark cycle. Food and water were provided ad libitum. The day of birth was considered P0 and litters were culled to 12 pups (6 males and 6 females) on P1. No more than one male and one female from the same litter were used for one experimental group. Pups were separated from the mother only for the duration of the session (maximum $1 \mathrm{~h}$ ).

Adolescents: We used 47 male and destabilize memories and is thought to be one of the causes of infantile amnesia (for review, see Madsen and Kim 2015). Rapamycin, through its action on mTOR, may have decreased neurogenesis (for review, see Tee et al. 2016) in key structures for threat learning (like the amygdala) and, as a result, improved the retention of the memory formed during reactivation. Thus, decreasing neurogenesis at an early age may benefit, rather than disrupt, the new memory that is incorporated during the reactivation. Further experiments are needed to evaluate each of these possibilities.

In sum, our results show that while prediction error detection and temporal processing seem mature in preweaning rats, specific infant-type mechanisms are at play for updating threat memories. Whether they are related to the maturation of specific neural networks and/or of different molecular underlying mechanisms remains to be elucidated. Our results highlight the fact that reactivation of a memory can elicit different processes: prediction error detection, updating and reconsolidation, and that those processes may mature differentially across development.

A Adolescents

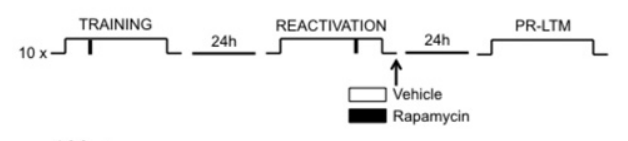

B female PN30-40 Long Evans rats born and bred in our colony (originally from Harlan Laboratories). Rats were housed in polypropylene cages $(34 \times 29 \times 17 \mathrm{~cm})$ with same-sex littermates (four per cages) and maintained in a $20^{\circ} \mathrm{C} \pm 1^{\circ} \mathrm{C}$ environment with a $12 / 12 \mathrm{~h}$ light-dark cycle. Food and water were provided ad libitum. No more than one male and one female from the same litter were used for one experimental group.

Adults: We used 53 adults male Sprague Dawley rats ( $>$ PN60) provided by Hilltop Lab Animals, weighing 250-300 g at the beginning of the experiment. Rats were single housed in polypropylene cages $(34 \times 29 \times 17 \mathrm{~cm})$ and maintained in a $20^{\circ} \mathrm{C} \pm 1^{\circ} \mathrm{C}$ environment with a $12 / 12 \mathrm{~h}$ light-dark cycle. Food and water were provided ad libitum.

All procedures were in accordance with the NIH Guide for the Care and Use of Experimental Animals, and were approved by the Nathan Kline Institute, NYU School of Medicine's, and NYU Animal Welfare University Committees.

\section{Behavioral apparatus and stimuli}

We used four identical chambers constructed of aluminum and Plexiglas (Mouse Test Cage for preweaning and Rat Test Cage
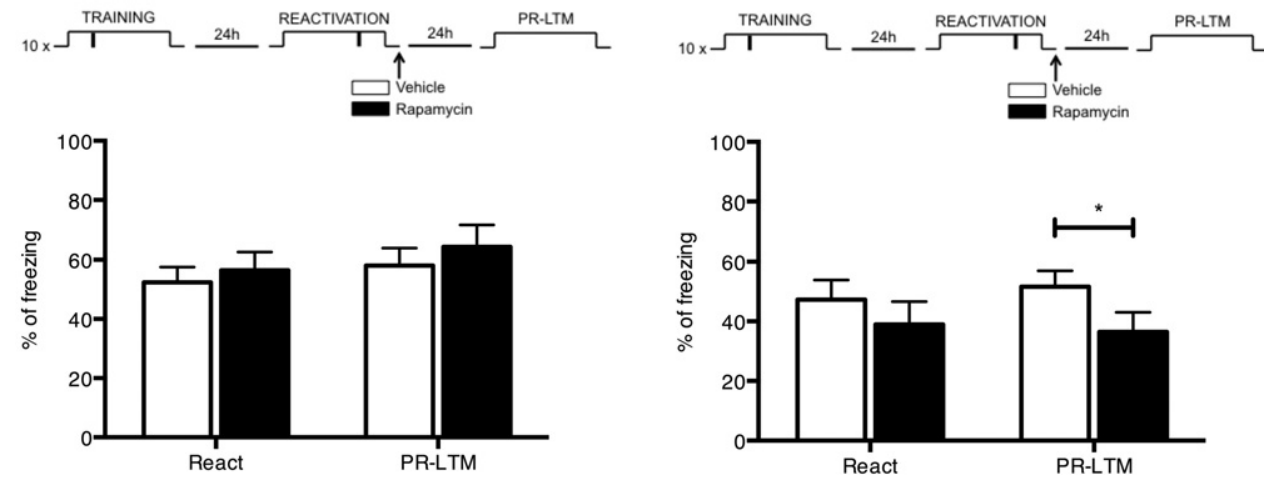

Figure 5. Comparison across development of the effect of rapamycin after a shift in the CS-US interval. The two experiments consisted of training with 10 trials of a 40 -sec tone (CS) paired with a US footshock delivered $10 \mathrm{sec}$ after tone onset. Rats were reactivated with the presentation of a single CS-US trial with the US delivered $30 \mathrm{sec}$ after the tone onset. Each panel shows a schematic of the experimental design (top) and the percentage of freezing $($ mean + SEM) to the first $10 \mathrm{sec}$ of the CS during reactivation (React) and during the post-reactivation long-term memory (PR-LTM) test in adolescents ( $A$, PN30-40, $n=12$ per group) and adults ( $B,>$ PN60, $n=14$ per group) injected with vehicle (white bars) or with rapamycin (black bars) (bottom). Freezing during reactivation was equivalent between vehicle and rapamycin groups in both experiments. The injection of rapamycin after reactivation had no effect in adolescents on the freezing in the PR-LTM test $(A)$ but provoked a significant decrease in adult freezing during the PR-LTM $(B)$. $\left(^{*}\right) P<0.05$. 
for adults and adolescents, Coulbourn Instruments, Allentown, PA), with metal stainless steel rod flooring that was connected to a shock generator (Model H13-15; Coulbourn Instruments). The chambers were enclosed within a sound-isolation cubicle (Model H10-24A; Coulbourn Instruments). Habituation, conditioning, and reactivation took place in context 1 which consisted of a grid floor, a yellow house light and was cleaned with ethanol. Cue test took place in context 2 which consisted of a plastic board covering the grid, a red house light, and was cleaned with Windex. Chamber grid floors, trays, and walls were thoroughly cleaned after each session. Rats were allowed to freely explore the chamber before each behavioral procedure for a variable amount of time depending on the sessions ( $10 \mathrm{~min}$ for threat conditioning, $4 \mathrm{~min}$ for reactivation, and $5 \mathrm{~min}$ for test session). The conditioned stimulus (CS) was a $40 \mathrm{sec}, 5 \mathrm{kHz}, 80 \mathrm{~dB}$ tone (background of $70 \mathrm{~dB}$ ). The unconditioned stimulus (US) was a 0.5 -sec footshock with an intensity of $0.6 \mathrm{~mA}$.

An infrared digital camera, mounted on top of each chamber, allowed recording during behavioral procedures for later behavioral scoring. Stimulus presentation and behavior recording was controlled through a computer equipped with Freeze Frame software (Coulbourn Instruments) for pups and adolescents, and Graphic State Software (Coulbourn Instruments) for adults.

\section{Aversive conditioning and memory procedures}

\section{Handling}

All animals were handled for $2 \mathrm{~d}$ before the start of the experiment. PN18-20 pups were removed from the nest in pairs and manipulated for $5 \mathrm{~min}$. Adolescents were also handled by pairs to reduce stress, whereas adults were handled separately.

\section{Aversive conditioning procedure}

All rats were exposed to the conditioning context during $30 \mathrm{~min}$ for habituation to the context 1 (Day 1 ), or for $1 \mathrm{~h}$ in two consecutive days for the adults. Twenty-four hours after, rats were placed in context 1 and CS-US trials were delivered. The US was delivered 30 or $10 \mathrm{sec}$ after the onset of the 40 -sec CS depending on the group. Mean inter-trial interval was $4 \mathrm{~min}$ from the following durations $3,3.5,4,4.5$, or $5 \mathrm{~min}$. Rats were conditioned with either 5 CS-US or 10 CS-US pairings.

\section{Memory reactivation}

The memory reactivation session took place $24 \mathrm{~h}$ after conditioning and in context 1 . A single presentation consisting of either a CS-US pairing (with a 30 or a 10 -sec CS-US interval) or a CS alone was presented 4 min after placement in the context. The US was delivered either at the same time after the tone onset as during conditioning (No Shift groups, 30-30 sec or 10-10 sec), or at a different time after the tone onset than during conditioning (Shift groups, Earlier or Later). Immediately after exposure to the stimulus, the rats received an intraperitoneal (i.p.) injection of either rapamycin (LC Laboratories, $10 \mathrm{mg} / \mathrm{mL}$ diluted in water with $10 \%$ DMSO and $10 \%$ Tween $20,20 \mathrm{mg} / \mathrm{kg}$, or $40 \mathrm{mg} / \mathrm{kg}$ ), or vehicle. The nonreactivated rats were simply removed from the home cage for the injection.

\section{Post-reactivation long-term memory (PR-LTM) test}

The retention test, done in context 2 , was performed $24 \mathrm{~h}$ after the drug injection. The memory retention test consisted of the presentation of one CS alone.

\section{Measurement of freezing behavior}

Freezing was used to measure the conditioned emotional aversive response, and was defined as the cessation of all movement with the exception of respiration-related movement and nonawake or rest body posture. Freezing was scored via the Freeze Frame software with a fixed threshold of 12 and a minimal bin size of 0.25 sec for the pups and verified by hand scoring by an observer blind to the conditions. For adolescents and adults, freezing was scored manually also by an observer blind to the conditions. Freezing was measured during the $40 \mathrm{sec}$ before the onset of the CS and the $40 \mathrm{sec}$ of the CS for both reactivation and PR-LTM sessions.

\section{Statistical analysis}

The analyses were performed with GraphPad Prism v6.0. Data were analyzed for each vehicle vs. rapamycin comparison by using unpaired $t$-test assuming equal variance after performing the unpaired $F$-test for variance, as well as two-way ANOVAs. The significance level was set at $\alpha=0.05$.

\section{Acknowledgments}

This research was supported by the following grants: Fulbright (L.T.), CNRS-NYU LIA LearnEmoTime (V.D., R.M.S., A.-M.M., J.E.L), PUF Emotion \& Timing (V.D., R.M.S., A.-M.M., J.E.L.), ANR grants (V.D.), NARSAD Young Investigator grant (L.D.M), LABEX CORTEX of Université de Lyon (A.-M.M), and NIH MH091451, HD083217 (R.M.S.). We thank Guillaume Ferreira for his helpful input on the results.

\section{References}

Alfei JM, Ferrer Monti RI, Molina VA, Bueno AM, Urcelay GP. 2015. Prediction error and trace dominance determine the fate of fear memories after post-training manipulations. Learn Mem 22: 385-400.

Baldi E, Bucherelli C. 2015. Brain sites involved in fear memory reconsolidation and extinction of rodents. Neurosci Biobehav Rev 53: 160-190.

Bernier PJ, Bedard A, Vinet J, Levesque M, Parent A. 2002. Newly generated neurons in the amygdala and adjoining cortex of adult primates. Proc Natl Acad Sci 99: 11464-11469.

Blundell J, Kouser M, Powell CM. 2008. Systemic inhibition of mammalian target of rapamycin inhibits fear memory reconsolidation. Neurobiol Learn Mem 90: 28-35.

Boulanger Bertolus J, Hegoburu C, Ahers JL, Londen E, Rousselot J, Szyba K, Thévenet M, Sullivan-Wilson T, Doyère V, Sullivan RM, et al. 2014. Infant rats can learn time intervals before the maturation of the striatum: evidence from odor fear conditioning. Front Behav Neurosci 8: $1-12$

Brannon EM, Roussel LW, Meck WH, Woldorff M. 2004. Timing in the baby brain. Cogn brain Res 21: 227-233.

Buhusi CV, Meck WH. 2005. What makes us tick? Functional and neural mechanisms of interval timing. Nat Rev Neurosci 6: 755-765.

Casey BJ, Tottenham N, Liston C, Durston S. 2005. Imaging the developing brain: what have we learned about cognitive development? Trends Cogn Sci 9: 104-110.

Clifton RK. 1974. Heart rate conditioning in the newborn infant. J Exp Child Psychol 18: 9-21.

Davis M, Schlesinger LS, Sorenson CA. 1989. Temporal specificity of fear conditioning: effects of different conditioned stimulus-unconditioned stimulus intervals on the fear-potentiated startle effect. J Exp Psychol Anim Behav Process 15: 295-310.

Díaz-Mataix L, Ruiz Martinez RC, Schafe GE, LeDoux JE, Doyère V. 2013. Detection of a temporal error triggers reconsolidation of amygdala-dependent memories. Curr Biol 23: 1-6.

Diaz-Mataix L, Santini E, Sarro EC, Perry RE, Tallot L, LeDoux JE, Klann E, Doyère V, Sullivan RM. 2014a. Ontogeny of molecular changes in the amygdala induced by odor-shock learning. Program No. 293.02. 2014 Neuroscience Meeting Planner. Society for Neuroscience, Washington, DC. Online.

Díaz-Mataix L, Tallot L, Doyère V. 2014b. The amygdala: a potential player in timing CS-US intervals. Behav Processes 101: 112-22.

Drew MR, Zupan B, Cooke A, Couvillon PA, Balsam PD. 2005. Temporal control of conditioned responding in goldfish. J Exp Psychol Anim Behav Process 31: 31-39.

Gisquet-Verrier P, Lynch JF, Cutolo P, Toledano D, Ulmen A, Jasnow AM, Riccio DC. 2015. Integration of new information with active memory accounts for retrograde amnesia: a challenge to the consolidation/ reconsolidation hypothesis? J Neurosci 35: 11623-11633.

Hung HC, Hsiao YH, Gean PW. 2015. Learning induces sonic hedgehog signaling in the amygdala which promotes neurogenesis and long-term memory formation. Int J Neuropsychopharmacol 18: 1-11.

Languille S, Gruest N, Richer P, Hars B. 2008. The temporal dynamics of consolidation and reconsolidation decrease during postnatal development. Learn Mem 15: 434-442. 
Mac Callum PE, Hebert M, Adamec RE, Blundell J. 2014. Systemic inhibition of mTOR kinase via rapamycin disrupts consolidation and reconsolidation of auditory fear memory. Neurobiol Learn Mem 112: 176-85.

Madsen HB, Kim JH. 2015. Ontogeny of memory: an update on 40 years of work on infantile amnesia. Behav Brain Res 298: 4-14.

Meck WH, Penney TB, Pouthas V. 2008. Cortico-striatal representation of time in animals and humans. Curr Opin Neurobiol 18: 145-152.

Moriceau S, Sullivan RM. 2006. Maternal presence serves as a switch between learning fear and attraction in infancy. Nat Neurosci 9: 1004-1006.

Nader K, Schafe GE, Le Doux JE. 2000. Fear memories require protein synthesis in the amygdala for reconsolidation after retrieval. Nature 406: $722-726$.

Nonneman AJ, Corwin JV. 1981. Differential effects of prefrontal cortex ablation in neonatal, juvenile, and young adult rats. J Comp Physiol Psychol 95: 588-602.

Pattwell SS, Mouly A-M, Sullivan RM, Lee F. 2013. Developmental transitions in fear across the life span: ecological significance. In Neurobiology of mental illness (ed. Charney D, Buxbaum J, Sklar P, Nestler E), pp. 593-605. Oxford University Press, Oxford.

Sara SJ. 2000. Retrieval and reconsolidation: toward a neurobiology of remembering. Learn Mem 7: 73-84.
Saunders NR, Liddelow SA, Dziegielewska KM. 2012. Barrier mechanisms in the developing brain. Front Pharmacol 3: 46.

Shionoya K, Moriceau S, Lunday L, Miner C, Roth TL, Sullivan RM. 2006. Development switch in neural circuitry underlying odor-malaise learning. Learn Mem 13: 801-808.

Stanton ME, Freeman JH, Skelton RW. 1992. Eyeblink conditioning in the developing rat. Behav Neurosci 106: 657-665.

Sullivan RM, Landers M, Yeaman B, Wilson DA. 2000. Good memories of bad events in infancy. Nature 407: 38-39.

Suzuki A, Josselyn SA, Frankland PW, Masushige S, Silva AJ, Kida S. 2004. Memory reconsolidation and extinction have distinct temporal and biochemical signatures. J Neurosci 24: 4787-4795.

Tallot L, Doyère V, Sullivan RM. 2015. Developmental emergence of fear/ threat learning: Neurobiology, associations and timing. Genes Brain Behav 15: 144-154.

Tee AR, Sampson JR, Pal DK, Bateman JM. 2016. The role of mTOR signalling in neurogenesis, insights from tuberous sclerosis complex. Semin Cell Dev Biol 52: 12-20.

Van Eden CG, Uylings HB. 1985. Cytoarchitectonic development of the prefrontal cortex in the rat. J Comp Neurol 241: 253-267.

Received May 31, 2016; accepted in revised form December 30, 2016. 


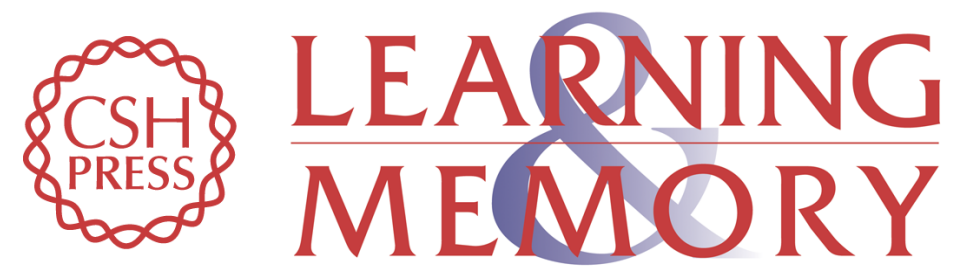

\section{Updating of aversive memories after temporal error detection is differentially modulated by mTOR across development}

Lucille Tallot, Lorenzo Diaz-Mataix, Rosemarie E. Perry, et al.

Learn. Mem. 2017, 24:

Access the most recent version at doi:10.1101/Im.043083.116

References This article cites 31 articles, 7 of which can be accessed free at:

http://learnmem.cshlp.org/content/24/3/115.full.html\#ref-list-1

Creative This article is distributed exclusively by Cold Spring Harbor Laboratory Press for the

Commons

first 12 months after the full-issue publication date (see

License http://learnmem.cshlp.org/site/misc/terms.xhtml). After 12 months, it is available under a Creative Commons License (Attribution-NonCommercial 4.0 International), as described at http://creativecommons.org/licenses/by-nc/4.0/.

Email Alerting Receive free email alerts when new articles cite this article - sign up in the box at the Service top right corner of the article or click here. 